\title{
ADDITIONS TO THE ORIBATID MITE FAUNA (ACARI, ORIBATIDA) OF ETHIOPIA, WITH REMARKS ON SOME SPECIES OF GALUMNIDAE
}

\author{
Luis S. Subías ${ }^{1}$, Sergey G. Ermilov²*, Umukusum Ya. Shtanchaeva1 \\ and Leonid B. Rybalov ${ }^{3}$
}

${ }^{1}$ Complutense University, Madrid, Spain

${ }^{2} \mathrm{X}-\mathrm{BIO}$ Institute, Tyumen State University, Tyumen, Russia

${ }^{3}$ A.N. Severtsov Institute of Ecology and Evolution, Moscow, Russia

*corresponding author; e-mail: ermilovacari@yandex.ru

\begin{abstract}
This study is based on the oribatid mite material collected in Ethiopia in 2020. A list of identified taxa, including 38 species from 29 genera and 20 families, is provided. Of these, six species are recorded for the first time in the Afrotropical region, and five species are recorded for the first time in Ethiopia. Supplementary descriptions and illustrations, as well as taxonomic data on two species of the family Galumnidae (Galumna lanceosensilla Ermilov, Sidorchuk and Rybalov, 2011 and Taeniogalumna behanae Ermilov, Sidorchuk and Rybalov, 2010) are presented.
\end{abstract}

KEY WORDS: List of taxa, new record, taxonomy, morphology, Galumna lanceosensilla, Taeniogalumna behanae, Afrotropical region.

DOI: 10.21684/0132-8077-2021-29-1-11-16

\section{INTRODUCTION}

This work is based on the oribatid mite material (Acari, Oribatida) collected in the course of the Joint Russian-Ethiopian Biological Expedition in the Amhara Region, Semien Shewa Zone, near Debre Berhan, Ethiopia in March, 2020. The primary goal of our paper is to present a list of the identified taxa with notes on the new records.

Our secondary goal is to update the main morphological traits of two species of the family Galumnidae: Galumna lanceosensilla Ermilov, Sidorchuk and Rybalov, 2011 and Taeniogalumna behanae Ermilov, Sidorchuk and Rybalov, 2010. Both species were described by Ermilov et al. (2010, 2011, respectively). However, the original descriptions are not complete. Therefore, we add new figures and information on some diagnostic morphological structures, which will help with the identification of these species in the future.

\section{MATERIALS AND METHODS}

Specimens. Substrate samples (litter) containing oribatid mites were collected using a stainlesssteel frame $(50 \times 50 \mathrm{~cm})$ with a sieve (mesh size $2 \times 2 \mathrm{~cm}$ ) from the following locality: Ethiopia, Amhara Region, Semien Shewa Zone, near Debre Berhan, 10¹7'38.7" N, 03954'3.2" E, 2890 m a.s.1., Juniperus forest, March 17, 2020 (collected by L.B. Rybalov). Mites were extracted into $75 \%$ ethanol using Berlese's funnels with electric lamps in laboratory conditions. The identified material has been deposited in the Tyumen State University Museum of Zoology, Tyumen, Russia.
Observation and documentation. Specimens were mounted in lactic acid on temporary cavity slides for measurement and illustration. Body length was measured in lateral view, from the tip of the rostrum to the posterior edge of the notogaster. Notogastral width refers to the maximum width of the notogaster in dorsal view. Lengths of body setae were measured in lateral aspect. All body measurements are presented in micrometers $(\mu \mathrm{m})$. Formulas for leg setation are given in parentheses according to the sequence trochanter-femur-genutibia-tarsus (famulus included). Formulas for leg solenidia are given in square brackets according to the sequence genu-tibia-tarsus. Drawings were made with a camera lucida using a Leica DM 2500 transmission light microscope.

Terminology. Morphological terminology used in this paper follows that of Grandjean (see Ermilov and Klimov [2017] for review and application).

Abbreviations. Prodorsum: $L$ - lamellar line; $S$-sublamellar line; $N$-prodorsal leg niche; $E$, $T$-lateral ridges of prodorsum; ro, le, in, $b s$-rostral, lamellar, interlamellar and bothridial seta, respectively; $A d$ - dorsosejugal porose area; $D$ dorsophragma; $P$ - pleurophragma. Notogaster: $c$, $l a, l m, l p, h, p$ —setal alveoli; $A a, A 1, A 2, A 3$ - porose areas; ia, im, ip, ih, ips-lyrifissures; glaopisthonotal gland opening. Epimeral and lateral podosomal regions: $e b$ - epimeral band; $1 a, 1 b, 3 b$, $3 c, 4 a, 4 b, 4 c$ - epimeral setae; PdI, PdII-pedotectum I, II, respectively; dis-discidium; $c p c$ circumpedal carina. Anogenital region: $g$, ag, an, $a d$-genital, aggenital, anal and adanal seta, re- 
spectively; iad —adanal lyrifissure; po-preanal organ.

\section{LIST OF IDENTIFIED TAXA*}

\section{Brachychthoniidae}

Liochthonius tyrrhenicus Bernini, 1985: 6 ex. Distribution: western Mediterranean. New record of the species in the Afrotropical region.

Liochthonius perelegans Moritz 1976: 1 ex. Distribution: central and western Europe. New record of the species in the Afrotropical region.

Nothridae

Nothrus crassisetus Mahunka 1982: 11 ex. Distribution: Ethiopia.

\section{Crotoniidae}

Camisia horrida (Hermann, 1804): 11 ex. Distribution: Holarctic, northern Oriental and northern Neotropical regions, Ethiopia.

Heminothrus glaber Mahunka, 1984: 2 ex. Distribution: Afrotropical region.

\section{Licnodamaeidae}

Lyrifissiella africana (Pletzen, 1963): 5 ex. Distribution: Afrotropical region.

\section{Aleurodamaeidae}

Aleurodamaeus recenfesevpi Ermilov and Rybalov 2012: >20 ex. Distribution: Ethiopia.

\section{Damaeidae}

Metabelba platynota Grandjean, 1954: 2 ex. Distribution: southern Europe. New record of the species in the Afrotropical region.

Metabelba sphagni Strenzke, 1950: 1 ex. Distribution: Euro-Atlantic. New record of the species in the Afrotropical region.

\section{Liacaridae}

Liacarus coracinus (Koch, 1841): 5 ex. Distribution: Palaearctic and Afrotropical regions.

Liacarus paratanzicus Ermilov, Rybalov and Kemal, 2011: 1 ex. Distribution: Ethiopia.

\section{Eremulidae}

Eremulus flagellifer Berlese, 1908: 8 ex. Distribution: Cosmopolitan. New record of the species in Ethiopia.

\section{Dameolidae}

Fosseremus laciniatus (Berlese 1904): 12 ex. Distribution: Cosmopolitan.

\section{Eremobelbidae}

Eremobelba tuberculata Mahunka, 1982: 13 ex. Distribution: Ethiopia.

"Distribution: mostly from Subías (online version 2021). Ptyctimous mites: not included.

\section{Oppiidae}

Arcoppia rugosa (Mahunka 1974): >20 ex. Distribution: Afrotropical region.

Helioppia sol (Balogh 1959): 3 ex. Distribution: Afrotropical region, Vietnam.

Machuella ventrisetosa zehntneri Mahunka, 1977: 1 ex. Distribution: Oriental and Afrotropical regions. New record of the subspecies in Ethiopia.

Neoamerioppia africana (Kok, 1967): >20 ex. Distribution: Afrotropical and Sub-Antarctic regions.

Neoamerioppia csabai Mahunka and MahunkaPapp 2007: 12 ex. Distribution: Afrotropical region.

\section{Suctobelbidae}

Suctobelbella (Flagrosuctobelba) elegantula (Hammer, 1958): 2 ex. Distribution: Tropical and Subtropical regions. New record of the species in Ethiopia.

Suctobelbella (Ussuribata) cf. flagellata (Balogh, 1959): 3 ex. Distribution: Afrotropical region. New record of the species in Ethiopia.

Suctobelbella (Ussuribata) spirochaeta Mahunka 1983: 7 ex. Distribution: Afrotropical region, Japan.

Suctobelbila fonticula Hammer, 1975: >20 ex. Distribution: Algeria, Afrotropical region. New record of the species in Ethiopia.

\section{Dampfiellidae}

Beckiella opposita Mahunka, 1982: 2 ex. Distribution: Ethiopia.

\section{Tectocepheidae}

Tectocepheus velatus (Michael 1880): >20 ex. Distribution: Cosmopolitan.

\section{Scutoverticidae}

Scutovertex granulatus Mihelčič, 1957: 1 ex. Distribution: southern Palaearctic region. New record of the species in the Afrotropical region.

\section{Eremaeozetidae}

Mahunkaia sp.: 1 ex.

\section{Phenopelopidae}

Eupelops occultus (Koch, 1835) “sensu” PérezÍñigo (1993): 5 ex. Distribution: Palaearctic region. New record of the species in the Afrotropical region.

\section{Ceratozetidae}

Melanozetes sp.: $>20$ ex.

\section{Punctoribatidae}

Antarctozetes cf. depilatus (Berlese, 1910): 7

ex. Distribution: Afrotropical region.

\section{Scheloribatidae}

Scheloribates discifer Balogh, 1959: 2 ex. Distribution: Afrotropical region. 
Scheloribates latipes (Koch 1844): 6 ex. Distribution: Semicosmopolitan.

Scheloribates maximus Balogh, 1962: 2 ex. Distribution: Afrotropical region.

Scheloribates pallidulus (Koch 1841): 2 ex. Distribution: Cosmopolitan.

Perscheloribates ethiopicus (Mahunka 1986): 1 ex. Distribution: Afrotropical region.

\section{Galumnidae}

Galumna lanceosensilla Ermilov, Sidorchuk and Rybalov, 2011: 12 ex. Distribution: Afrotropical region.

Taeniogalumna behanae Ermilov, Sidorchuk and Rybalov, 2010: > 20 ex. Distribution: Ethiopia.

Trichogalumna nipponica (Aoki, 1966): 1 ex. Distribution: Semicosmopolitan.

Hence, we have found 38 species/subspecies from 29 genera and 20 families. Of these, five species are recorded for the first time in Ethiopia; six species are recorded for the first time in the Afrotropical region.

\section{SYSTEMATICS}

\section{Galumna lanceosensilla Ermilov, Sidorchuk and Rybalov, 2011}

Figs. 1-4

Main morphological traits. Measurements. Body color brown. Body length about 460-570. Integument. Surface of prodorsum, notogaster and ventral side without sculpturing and ornamentation. Prodorsum. Rostrum rounded. Lamellar line short, thin, straight, located dorsally on prodorsum; sublamellar line long, thin, curving backwards. Rostral, lamellar and interlamellar setae long, setiform, barbed; ro shortest, in longest. Bothridial seta long, narrowly lanceolate, barbed. Dorsosejugal porose area oval, located posteriorly to insertion of interlamellar seta. Dorsophragma distinctly elongated longitudinally. Notogaster. Dorsosejugal suture complete, but usually hardly visible medially. Ten pairs of setal alveoli $\left(c, l a, l m, l p, h_{1}-h_{3}\right.$ and $\left.p_{1}-p_{3}\right)$. Four pairs of porose areas ( $A a, A 1, A 2$ and $A 3) ; A a$ triangular or boot-shaped, others rounded or oval; Aa located close to pteromorphal hinge and anteriorly to setal alveolus $l a$. Median pore present between porose areas $A 2$. Opisthonotal gland opening located laterally to $A 1$. Lyrifissure im located close and anteriorly to $A 1$; ip between $p_{1}$ and $p_{2}$, slightly closer to the former; ih and ips close to each other, anteriorly to $p_{3}$. Gnathosoma. All subcapitular setae ( $a, m$ and $h$ ) setiform, slightly barbed; $a$ longest, $m$ shortest. Epimeral and lateral podosomal regions. Epimeral setal formula: 1-0-1-2; setae ( $1 a, 3 b, 4 a$ and $4 b$ ) short setiform, thin, roughened to slightly barbed; $1 a$ and $3 b$ longer than $4 a$ and $4 b$. Circumpedal carina comparatively short, distinctly not reaching of insertion of $3 b$. Anogenital region. Genital, aggenital, anal and adanal setae short, setiform, thin, smooth to roughened; $g_{1}$ and $g_{2}$ longer than others. Anterior edge of genital plate with two setae. Aggenital seta located between genital and anal apertures, slightly closer to the former. Adanal setae $a d_{1}$ and $a d_{2}$ posteriorly, $a d_{3}$ laterally to anal plate. Distance $a d_{1}-a d_{2}$ shorter than $a d_{2}-a d_{3}$. Adanal lyrifissure located close and parallel to anal plate. Postanal porose area large, oval. Legs. Chaetome is typical for Galumnidae.

\section{Taeniogalumna behanae Ermilov, Sidorchuk and Rybalov, 2010}

Figs. 5-8

Main morphological traits. Measurements. Body color brown to dark brown. Body length about 410-470. Integument. Surface of prodorsum, notogaster and ventral side densely microgranulate (visible only under high magnification). Prodorsum. Rostrum rounded. Lamellar and sublamellar lines long, thin, parallel, curving backwards. Rostral, lamellar and interlamellar setae short, setiform, smooth to roughened; ro longest*, le slightly longer than in. Bothridial seta long, setiform, with shortly ciliate unilaterally in middle-distal part. Dorsosejugal porose area absent. Dorsophragma distinctly elongated longitudinally. Notogaster. Dorsosejugal suture complete, distinct. Ten pairs of setal alveoli $\left(c, l a, l m, l p, h_{1}-h_{3}\right.$ and $\left.p_{1}-p_{3}\right)$. Three pairs of rounded porose areas ( $A a, A 1$ and $A 3)$; $A a$ larger than others, located close to pteromorphal hinge and anteriorly to setal alveolus la. Median pore absent. Opisthonotal gland opening and lyrifissure im located close to each other and laterally to $A 1$. Lyrifissure ip located between $p_{1}$ and $p_{2}$, closer to the former, or posteriorly/posterolaterally to $p_{1}$; ih and ips close to each other, located anteriorly to $p_{3}$. Gnathosoma. All subcapitular setae ( $a, m$ and $h)$ setiform, smooth to roughened; $a$ longer than others.

"Ermilov et al. (2010) described rostral, lamellar and interlamellar setae of the same length; however, an additional examination of the materials of $T$. behanae showed that this statement was incorrect. Really, ro is longer than others. 


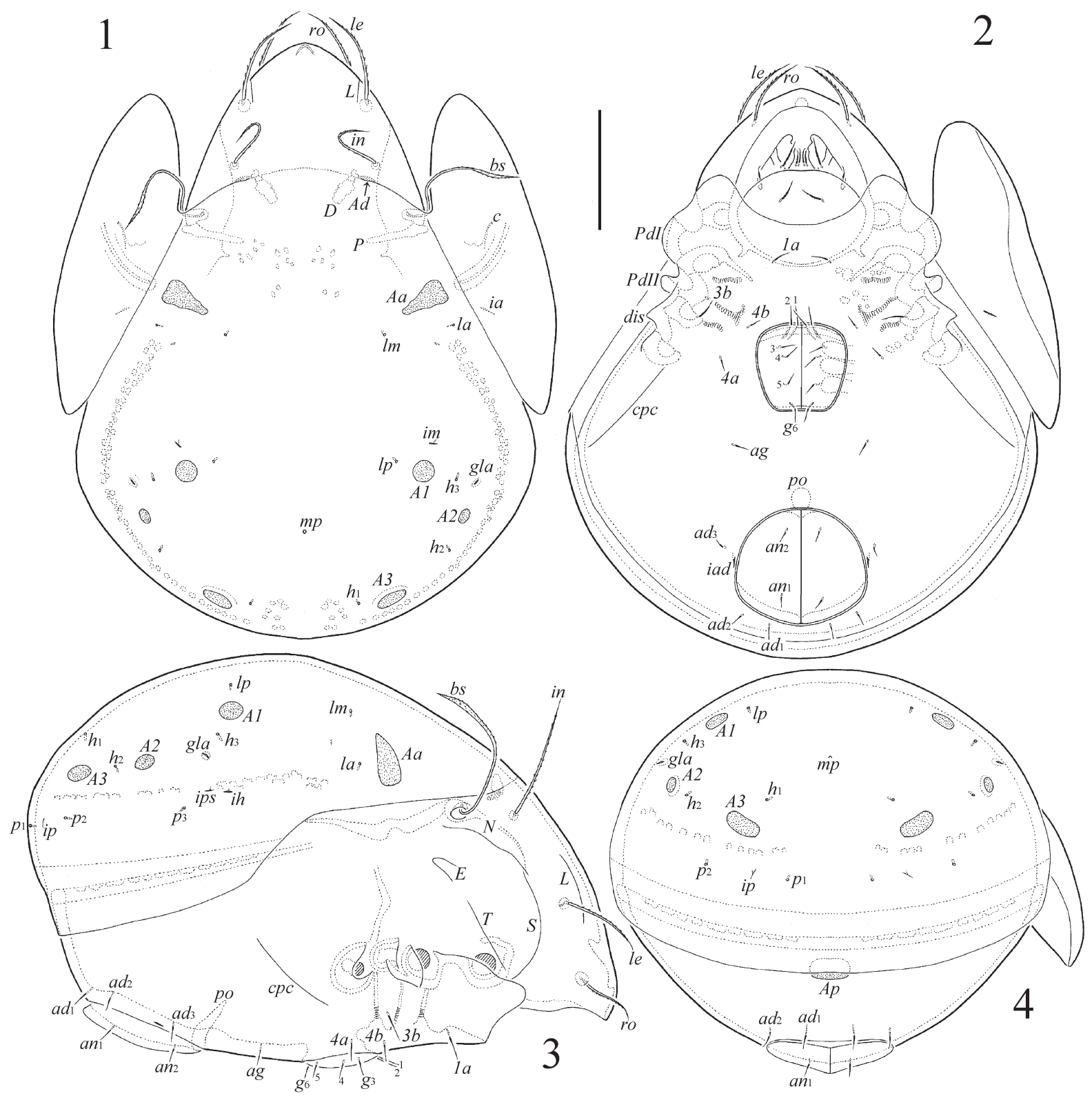

Figs. 1-4. Galumna lanceosensilla Ermilov, Sidorchuk and Rybalov, 2011, adult: 1-dorsal view; 2-ventral view (not shown: right pteromorph and legs); 3-right lateral view (not shown: pteromorph, gnathosoma and legs); 4posterior view (not shown: left pteromorph); Scale bar $=100 \mu \mathrm{m}$.

Epimeral and lateral podosomal regions. Transverse pigmented band well-developed or indistinct. Epimeral setal formula: 2[or 1 ; if $1 a$ absent]-0-2-3; setae ( $1 a, 1 b, 3 b, 3 c, 4 a, 4 b$ and $4 c)$ short setiform, thin, smooth to roughened; $l b$ and $3 b$ longer than others. Circumpedal carina comparatively short, distinctly not reaching insertion of $3 b$. Anogenital region. Genital, aggenital, anal and adanal setae short, setiform, thin, smooth to roughened; anal and adanal setae longer than others. Anterior edge of genital plate with two setae. Aggenital seta located between genital and anal apertures, equally distant from them. Ad- anal setae $a d_{1}$ and $a d_{2}$ posteriorly, $a d_{3}$ laterally to anal plate. Distance $a d_{1}-a d_{2}$ shorter than $a d_{2}-a d_{3}$. Adanal lyrifissure located close and parallel to anal plate. Postanal porose area absent. Legs. Chaetome is typical for Galumnidae. Seta v' on femur I very short.

Remarks. Taeniogalumna behanae was described by Ermilov, Sidorchuk and Rybalov (2010) and included in the genus Taeniogalumna Balogh, 1962, based on the presence of a well-developed transverse pigmented (dark brown) epimeral band (main generic character). However, this feature is invisible or partially visible (in median part, before 


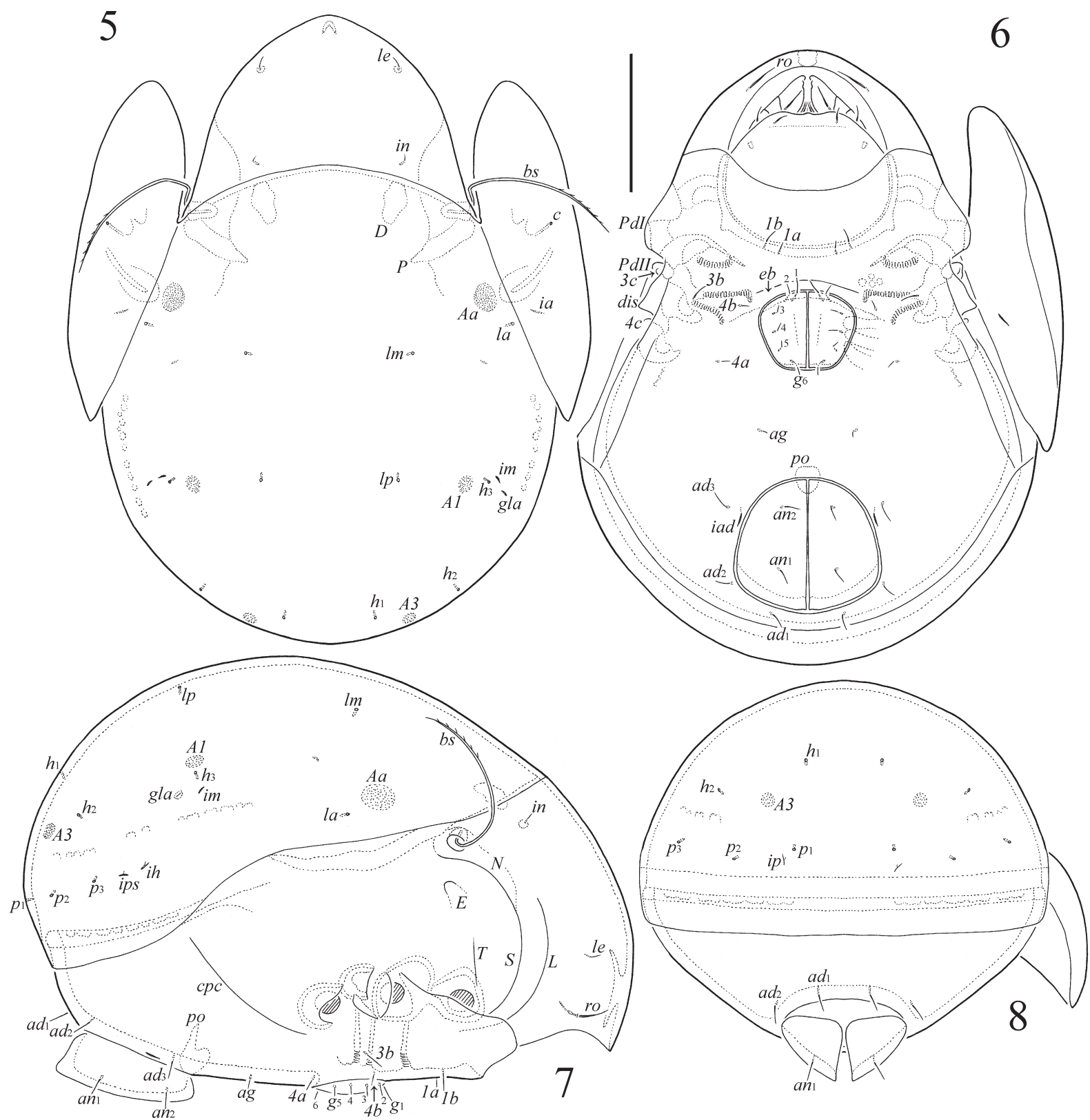

Figs. 5-8. Taeniogalumna behanae Ermilov, Sidorchuk and Rybalov, 2010, adult: 5-dorsal view; 6-ventral view (not shown: right pteromorph and legs); 7-right lateral view (not shown: pteromorph, gnathosoma and legs); 8posterior view (not shown: left pteromorph); Scale bar=100 $\mu \mathrm{m}$.

genital aperture) in new specimens from Amhara Region, Semien Shewa Zone, near Debre Berhan. This morphological nuance illustrates the similarity between $T$. behanae and the representatives of the genus Pergalumna Grandjean, 1936, especially with Pergalumna tanzanica Mahunka, 1984. Such similarity is observed in many traits: e.g., body of medium size; rostral, lamellar and interlamellar setae comparatively short; bothridial seta setiform, ciliate unilaterally; dorsosejugal porose area absent; dorsosejugal suture present; three pairs of rounded notogastral porose areas; median pore absent.
Taeniogalumna behanae can be distinguished from P. tanzanica in the following: 1) the localization of notogastral porose area $A a$ (close to pteromorphal hinge in T. behanae vs. removed from hinge in P. tanzanica); 2) localization of subcapitular seta $h$ (close to anterior margin of mentum in $T$. behanae vs. removed from anterior margin of mentum in $P$. tanzanica); 3) the morphology of bothridial seta (shortly ciliate in the middle-distal part in $T$. behanae vs. cilia longer, completely covering the seta in $P$. tanzanica); and 4) the length of anal and adanal setae (comparatively long in $T$. behanae vs. minute in P. tanzanica). 


\section{ACKNOWLEDGEMENTS}

This work was performed within the framework of the Joint Russian-Ethiopian Biological Expedition, financially supported by the Russian Academy of Sciences. This research was partially supported by a grant from the Russian Science Foundation (project No. 19-14-00004).

\section{REFERENCES}

Ermilov, S. G. and Klimov, P.B. 2017. Generic revision of the large-winged mite superfamily Galumnoidea (Acari, Oribatida) of the world. Zootaxa, 4357 (1): $1-72$.
Ermilov, S.G., Sidorchuk, E.A. and Rybalov, L.B. 2010. New species of oribatid mites of the superfamily Galumnoidea (Acari: Oribatida) from Ethiopia. Zootaxa, 2646: 43-62.

Ermilov, S.G., Sidorchuk, E.A. and Rybalov, L.B. 2011. Three new species of oribatid mites (Acari: Oribatida: Galumnoidea) from Ethiopia. International Journal of Acarology, 37 (Supplement 1): $2-17$.

Subías, L.S. 2021. Listado sistemático, sinonímico y biogeográfico de los Ácaros Oribátidos (Acariformes: Oribatida) del mundo (excepto fósiles), $16^{\mathrm{a}}$ actualización. $532 \mathrm{pp}$. bba.bioucm.es/cont/ docs/RO_1.pdf 